\title{
Erratum to: Belowground nitrogen transfer from legumes to non-legumes under managed herbaceous cropping systems. A review
}

\author{
Malinda S. Thilakarathna ${ }^{1} \cdot$ Michel S. McElroy $^{2} \cdot$ Tejendra Chapagain $^{1}$. \\ Yousef A. Papadopoulos ${ }^{3} \cdot$ Manish N. Raizada ${ }^{1}$
}

Accepted: 16 September 2016 /Published online: 4 November 2016

(C) INRA and Springer-Verlag France 2016

Erratum to: Agron. Sustain. Dev.

DOI: 10.1007/s13593-016-0396-4

The reference to "Thilakarathna RMMS (2016) Genotypic variability among diverse red clover cultivars for nitrogen fixation and transfer. PhD Thesis. Dalhousie Killam library" is incorrect.

The correct entry reads: Thilakarathna RMMS (2013) Genotypic variability among diverse red clover cultivars for nitrogen fixation and transfer. PhD Thesis. Dalhousie Killam library

The year of publication is 2013. Also, the citation of the reference within the text should read "Thilakarathna 2013".

The online version of the original article can be found at http://dx.doi. org/10.1007/s13593-016-0396-4.

Malinda S. Thilakarathna

mthilaka@uoguelph.ca

1 Department of Plant Agriculture, University of Guelph, Guelph, ON, Canada

2 Department of Biology, Dalhousie University, Halifax, NS, Canada

3 Agriculture and Agri-Food Canada, Faculty of Agriculture,

Dalhousie University, Truro, NS, Canada 